\section{Kidney \\ Blood Pressure Research}

Kidney Blood Press Res 2017;42:1-15

DOI: 10.1159/000464312

Published online: February 28, 2017

(C) 2017 The Author(s)

Published by S. Karger AG, Basel

www.karger.com/kbr

\title{
Disease Progression Modeling to Evaluate the Effects of Enzyme Replacement Therapy on Kidney Function in Adult Patients with the Classic Phenotype of Fabry Disease
}

\author{
Albina Nowak ${ }^{\mathrm{a}}$ Gilbert Koch ${ }^{\mathrm{b}} \quad$ Uyen Huynh-Doc Martin Siegenthalera \\ Hans-Peter Marti ${ }^{d}$ Marc Pfister ${ }^{b}$
}

\begin{abstract}
aDepartment of Internal Medicine, University Hospital Zurich and University of Zurich, Zurich; ${ }^{b}$ Department of Pediatric Clinical Pharmacology, Pediatric Pharmacology and Pharmacometrics Research Center, University of Basel Children's Hospital (UKBB), Basel; 'Department of Nephrology, Hypertension and Clinical Pharmacology, Department of Clinical Research, Inselspital, University of Bern, Switzerland; 'Department of Medicine, Haukeland University Hospital, Bergen, Norway; Department of Clinical Medicine, University of Bergen, Bergen, Norway
\end{abstract}

\section{Key Words}

Enzyme replacement therapy $\bullet$ Fabry disease $\cdot$ Classic phenotype $\cdot$ Modeling $\bullet$ Nephropathy

\begin{abstract}
Background/Aims: Fabry disease (FD) is a rare inherited lysosomal storage disease with common and serious kidney complications. Enzyme replacement therapies (ERT) with agalsidase- $\alpha$ and $-\beta$ were investigated to characterize their therapeutic effect on kidney function in FD patients with Classic phenotype. Methods: The prospective FD cohort consisted of 98 genetically confirmed patients (females, $n=61$, males, $n=37$ ). The median [interquartile range] follow-up time (time difference from first to last visit) was 9 [6, 12] years. The median age of ERT start was 36 [21 - 54] years for females and 39 [28 - 49] years for males. Results: A disease progression model was developed to (i) characterize the time course of estimated glomerular filtration rate (eGFR) and (ii) evaluate therapeutic effects of ERT on kidney function. Change in eGFR over time was best described by the linear model. Females had stable kidney function with and without ERT (eGFR slopes of $-0.07 \mathrm{ml} / \mathrm{min} / 1.73 \mathrm{~m}^{\wedge} 2$ per year and $0.52 \mathrm{ml} /$ $\min / 1.73 \mathrm{~m}^{\wedge} 2$ per year, respectively). Males with ERT showed an eGFR decrease of $-3.07 \mathrm{ml} /$ $\min / 1.73 \mathrm{~m}^{\wedge} 2$ per year. Conclusion: Mathematical disease progression modeling indicates that there is no clear therapeutic effect of ERT on kidney function in adult patients with Classic
\end{abstract}




\section{Kidney Blood Pressure Research}

Phenotype of FD. Interpretation of these findings should take into account that the study is not randomized and lacks a placebo controlled group. Further investigations are warranted to clarify whether earlier ERT initiation before 18 years of age, higher ERT dose or more intensive therapies can preserve kidney function.

\section{Introduction}

Fabry disease (FD) is a rare X-linked lysosomal storage disorder caused by a deficiency of the enzyme $\alpha$-galactosidase A $(\alpha$-Gal A) resulting in a progressive intralysosomal accumulation of glycosphingolids in different cell types, plasma and urine $[1,2]$. In a majority of patients, initial signs and symptoms related to FD appear in childhood and include acroparaesthesia, angiokeratoma, abdominal pain, hypohidrosis and corneal dystrophy. Inflammation and fibrosis associated with disease progression leads to kidney and heart failure, cerebrovascular disease and early mortality [1]. Deposition of undergraded glycosphingolipid substrate occur in all kidney cells and structures including podocytes, mesangial, tubular, interstitial and vascular endothelial cells [3]. Fabry nephropathy is linked to cardiovascular morbidity and mortality in FD patients [4]. Although males have more severe Fabry disease than females, heterozygous females with X-chromosomal inactivation can also be severely affected depending on random X-chromosomal inactivation [5]. "Classic" and "Later-Onset" phenotypes are the two major FD subtypes. Affected males with the Later-Onset phenotype have residual $\alpha$-Gal A activity, later-onset cardiac and/or renal disease, and lack the major early-onset classical manifestations, including angiokeratoma, acroparesthesias, hypohidrosis, and the ocular abnormalities [6-9].

Enzyme replacement therapy (ERT) with recombinant $\alpha$-Gal A was approved in Europe in 2001. There are two preparations available on the market: agalsidase- $\alpha$ with the licensed dose of $0.2 \mathrm{mg} / \mathrm{kg}$ or agasidase $\beta$ dosed at $1 \mathrm{mg} / \mathrm{kg}$ body weight, each administered every 2 weeks intravenously. ERT initiation is recommended in classically affected males and females as soon as early clinical signs of FD occur [10]. Studies have shown a kidney tissue clearance of glycosphingolipid accumulation as a result of ERT [11], long-term ERT stabilized and preserved kidney function in some FD patients [12-14]. Recent studies suggest that FD patients with chronic kidney disease (CKD) stage 3 or 4 may not benefit from ERT as clinically meaningful events continue to occur in these patients despite treatment [15]. Proteinuria seems to be associated with decreased effectiveness of ERT $[16,17]$.

To further enhance treatment strategies for FD patients, key determinants of variability in kidney disease progression in FD patients with and without ERT need to be identified and characterized. For this reason a longitudinal, mathematical model was developed [18] to (i) account for individual behavior of female and male FD patients, (ii) characterize individual model parameters and the inter-individual variability, (iii) identify and quantify effects of covariates on kidney disease progression, measured as change in kidney function (eGFR) over time. In order to analyze a homogeneous group, the performed disease progression analysis focused on patients with the Classic phenotype of FD.

\section{Subjects and Methods}

This is a retrospective analysis of a prospective, multi-center cohort in Switzerland. The study was conducted in accordance with the principles of Helsinki Declaration. Patients who were alive were contacted, and signed a written informed consent. 


\section{Kidney Blood Pressure Research}

Kidney Blood Press Res 2017;42:1-15
\begin{tabular}{l|l} 
DOI: 10.1159/000464312 & $\begin{array}{l}\text { ○ } 2017 \text { The Author(s). Published by S. Karger AG, Basel } \\
\text { www.karger.com/kbr }\end{array}$ \\
Published onlne: February 28, 2017
\end{tabular}

Nowak et al.: ERT and Kidney Function in Classic FD Phenotype

\section{Study population and clinical data}

The prospective FD cohort consisted of 98 genetically confirmed patients (females, $n=61$, males, $n=$ 37). The cohort was established in 2001 when ERT was approved and offered to FD patients. Consecutive FD patients were registered and monitored at two tertiary care hospitals - University Hospitals Zürich (90 patients) and Bern (8 patients) Switzerland. Patients on renal replacement therapy (RRT) - kidney transplantation or dialysis ( $n=5$ all male $)$ - at baseline and patients with the Later-Onset phenotype $(n=9)$ were excluded from the analysis.

The analysis included all available renal data extracted from the FD patients` medical records until kidney transplantation ( $\mathrm{n}=5)$, death $(\mathrm{n}=10)$ or March 2015. Kidney function, expressed as eGFR according to Chronic Kidney Disease Epidemiology Collaboration (CKD-EPI) equation [19], and proteinuria, expressed as protein/creatinine or albumin/creatinine ratio, were analyzed. Information on concomitant angiotensinconverting enzyme (ACE)-inhibitors and angiotensin-receptor blockers (ARB) therapy was also recorded and analyzed as covariates. Kidney biopsies were performed in 11 patients, 6 males and 5 females, all the biopsies confirmed the Fabry nephropathy.

\section{Treatment}

ERT was initiated according to the written local guidelines. Accordingly, ERT was indicated in all males, independent from age, phenotype and symptoms. In females, ERT was indicated if they had proteinuria of more than 300 mg per day, Fabry-typical kidney biopsy findings, signs of Fabry cardiopathy such as left ventricular hypertrophy or arrhythmia, stroke or transient ischemic attack (TIA), persistent FD-related neuropathic pains despite conventional analgetic therapy, and or gastrointestinal symptoms.

In all patients, ERT was prescribed at the licensed dose of either $0.2 \mathrm{mg} / \mathrm{kg}$ body weight of recombinant agalsidase- $\alpha$ (Replagal) or $1 \mathrm{mg} / \mathrm{kg}$ body weight agalsidase- $\beta$ (Fabrazyme) and given intravenously every 14 days. We retrospectively calculated the actual, administered ERT amount per kg by multiplying the dose contained in a vial by the number of vials and divided this amount by the current body weight documented in the medical records at each visit. We separately computed cumulative doses for Replagal and Fabrazyme in patients who switched ERT. Cumulative doses were calculated according to the respective preparation of Replagal and Fabrazyme.

\section{Phenotyping}

Phenotyping was based on GLA mutation type: frame-shift, nonsense, consensus splice-site mutations, large insertions and deletions, and some missense mutations, which result in no or $<2 \%$ of mean normal enzymatic activity were classified as having the Classic phenotype. In contrast, some missense and some alternative splicing mutations result in enzymes with residual enzymatic activity and the Later-Onset phenotype. To determine, if the missense mutations caused the Classic or Later-Onset phenotype, clinical data, substrate levels, and in vitro expression assays were evaluated to determine the mutation's phenotype $[6,20,21]$.

\section{Assessment of kidney function}

As measure of kidney function, the eGFR was derived from serum creatinine $s c r(\mathrm{mg} / \mathrm{dL})$ and age (years) by the Chronic Kidney Disease Epidemiology Collaboration [19].

\section{Characterizing relationship between age and kidney function at baseline}

In a first step, the relation between age at baseline $\left(A g e_{\text {Base }}\right)$ and eGFR at baseline $\left(e G F R_{\text {Base }}\right)$ was investigated by linear regression

$$
e G F R_{\text {Base }}=a+m \cdot A g e_{\text {Base }}
$$

where $a$ is the intercept and $m$ the slope. Female ( 54 subjects) and male (25 subjects) were separately investigated.

Developing disease progression model to describe change in kidney function over time

In the second step, a disease progression model $[22,23]$ to describe eGFR change over time was developed. Data of every individual was shifted to the starting time point $t=0$. 


\section{Kidney Blood Pressure Research}

To describe eGFR change $e G F R(t)$ over time $t$ (months), the linear model

$$
e G F R(t)=e G F R_{\text {Base }}+e G F R_{\text {slope }} \cdot t
$$

where $e G F R_{\text {Base }}$ is the initial intercept at $t=0$ and $e G F R_{\text {Slope }}$ the slope, was most appropriate to describe available data. Also other disease progression models such as exponential decay or oscillating approaches were tested. However, estimated parameters for these models always produced a linear prediction, confirming our chosen linear model Eq. (2).

Incorporating of patient characteristics and covariate effects on kidney function in model

FD patients with more than one creatinine measurement were included into the dynamical analysis ( $n=67)$. Non-linear mixed effect modeling $[18,24]$ was applied to estimate the typical (also called mean or population) parameters and individual parameters. A normal distribution for the individual eGFR slopes $e G F R_{\text {Slope, } i}$ was assumed to allow negative values for $1 \leq i \leq n$ where $n$ is the number of individuals. Individual eGFR baselines $e G F R_{\text {Base }, i}$ were described best by a log-normal distribution. The variance of these parameter distributions is denoted by ${ }^{\omega} \theta_{\mathrm{k}}$ with $1 \leq k \leq n_{\text {parm }}$, where $n_{\text {parm }}=2$ is the number of model parameters. Categorical covariates $\operatorname{Cov}_{\text {Cat }}$, such as gender, were implemented at the individual model parameters $\theta_{\mathrm{i}, \mathrm{k}}$ with

$$
\theta_{i, k}=\theta_{\text {pop }, k}+\beta_{\text {Cov }_{\text {cat }, k}} \cdot \operatorname{Cov}_{\text {cat }}
$$

In Eq. (3), the effect of the individual covariate on the population parameter $\theta_{\text {pop, }}$ is described by

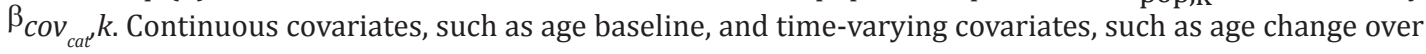
time, were implemented with the power model

$$
\theta_{i, k}=\theta_{p o p, k}\left(\frac{\operatorname{Cov}_{\text {Con }}}{\operatorname{Cov}_{\text {ref }}}\right)^{\beta_{\text {Cov }}{ }_{\text {con }, k}}
$$

where $\operatorname{Cov}_{\text {con }}$ is a covariate, $\operatorname{Cov}_{\text {ref }}$ a reference value of a given covariate and $\beta_{\operatorname{cov}_{\text {con }} k} k$ the coefficient describing the effect of the covariate. In our analysis, $\operatorname{Cov}_{r e f}$ was defined as the mean and estimated from data. Time-varying covariates were implemented as additional regression variables in the model.

Kindey disease progression model according to baseline albuminuria

Patients were categorized into three groups of albuminuria according to the recent KDIGO definitions [25]: A1 with albuminuria $<3 \mathrm{mg} / \mathrm{mmol}$, A2 $3-30 \mathrm{mg} / \mathrm{mmol}, \mathrm{A} 3>30 \mathrm{mg} / \mathrm{mmol}$. Computed individual slopes from the longitudinal analysis of treated FD patients were grouped into these three albuminuria categories. Albuminuria at baseline was defined as the first available measurement in each study patient.

\section{Analysis of serum-mediated ERT inhibition}

Between January 2014 and December 2016, blood for biobanking was drawn, blood samples were centrifuged and serum was immediately frozen at $-80^{\circ} \mathrm{C}$. ERT inhibition assays were performed as reported elsewhere [26-28] in 15 males and 20 females who were included into the dynamical analysis. The measurements have been performed as triplicates. Since ERT-inhibition develops within the first weeks after ERT treatment [26] and seems to be irreversible, serum samples from recent visits are most likely useful to reflect the inhibition status over the treatment period. Patients with a mean ERT inhibition $>50 \%$ were designated as ERT inhibition positive according to recent literature [27].

\section{Statistical-mathematical analyses}

Categorical variableswere expressed as proportions, continuous variables as medians with interquartile ranges [IQR]. All statistical tests were two-sided, and $\mathrm{p}$ values $<0.05$ were considered significant.

The dynamical analysis was performed with the non-linear mixed effect software package Monolix 4.3 [29]. The other analyses were performed using statistical software package R [30].

\section{Results}

Follow-up and treatment

The average number of visits was 5 per patient and the overall number of visits was 


\section{Kidney Blood Pressure Research}

Kidney Blood Press Res 2017;42:1-15

\begin{tabular}{l|l}
\hline DOI: 10.1159/000464312 & (C) 2017 The Author(s). Published by S. Karger AG, Basel
\end{tabular}

Published onlıne: February 28, 2017 www.karger.com/kbr

Nowak et al.: ERT and Kidney Function in Classic FD Phenotype
437. The median follow-up time of all included patients (time difference from first to last visit) was 9 [6-12] years. A total of $53 \mathrm{FD}$ patients were on ERT for at least $8[6-11]$ years. The median total cumulative dose of the patients receiving agalsidase- $\beta$ was $0.93 \mathrm{ml} / \mathrm{kg}$ [0.83 - 1.10] and agalsidase- $\alpha 0.20 \mathrm{ml} / \mathrm{kg}[0.18-0.21]$.

Females were started on ERT at 36 [21 - 54] years, males at 39 [28 - 49] years of age. Among treated females, the primary cause of ERT initiation was acroparesthesia $(n=8)$, cardiomypathy $(n=7)$, stroke $(n=3)$, renal involvement diagnosed by biopsy $(n=1)$, cardiomypathy and renal involvement $(\mathrm{n}=2)$.

Overall, 39 patients received agalsidase- $\alpha$ and four agalsidase- $\beta$ throughout the observational period. Six patients were switched from agalsidase- $\beta$
Table 1. Parameter estimates of linear regression Eq. (1) for the age at baseline and eGFR at baseline relationship

Estimate (s.e.)

$\begin{array}{lc}\text { Intercept female } & 133^{*}(4.7) \\ \text { Slope female } & -0.98^{*}(0.12) \\ \mathrm{R}^{\wedge} 2 & 0.54\end{array}$

Intercept male $133^{*}(16)$

Slope male $\quad-1.27^{*}(0.4)$

\begin{tabular}{ll}
$\mathrm{R}^{\wedge} 2$ & 0.29 \\
\hline
\end{tabular}

$* \mathrm{p}<0.01$

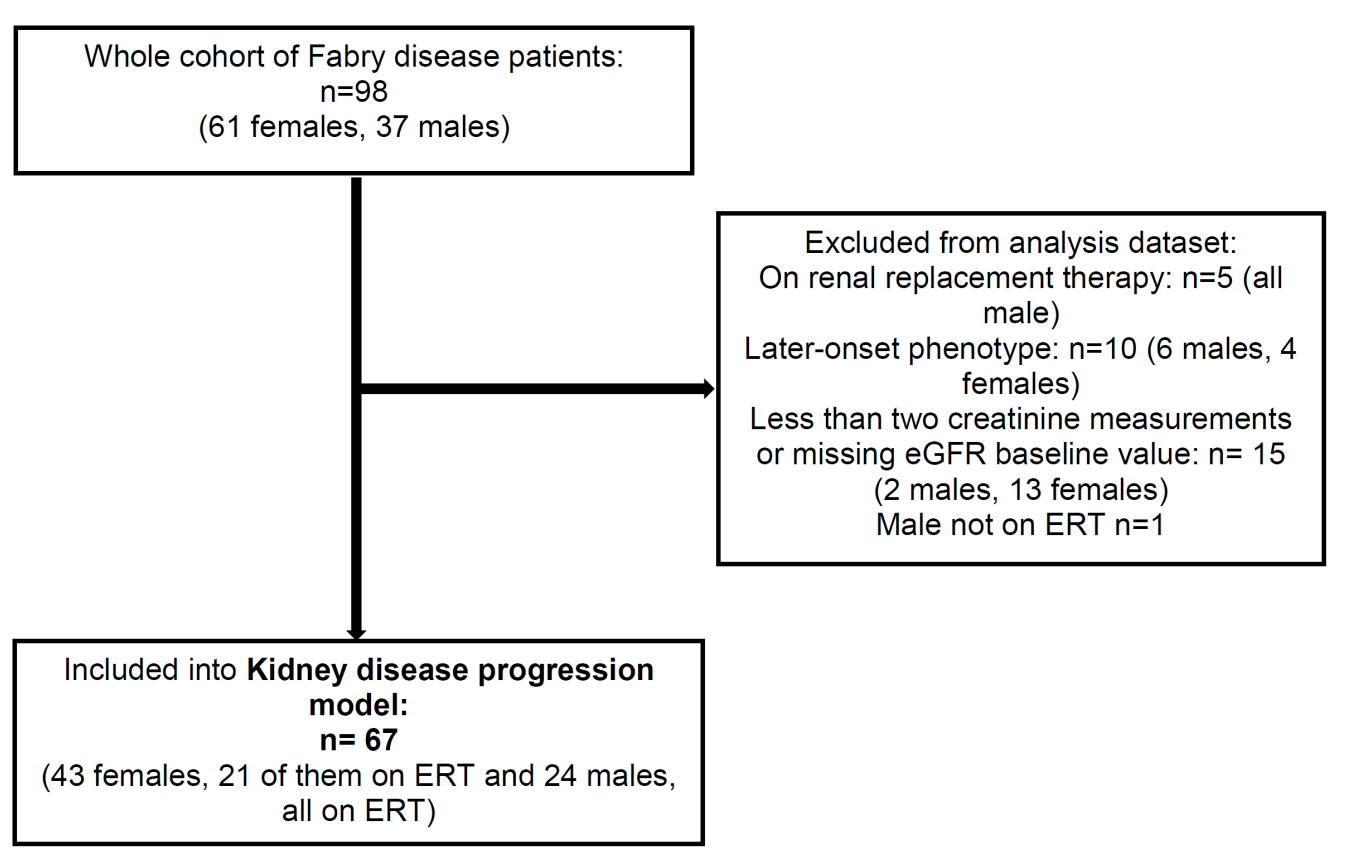

Fig. 1. Study flow-chart of the main analysis.

to agalsidase- $\alpha$ (due to shortage of agalsidase- $\beta$ ), two patients from agalsidase- $\alpha$ to agalsidase- $\beta$ (due to patient's priority) and two from agalsidase- $\alpha$ to agalsidase- $\beta$ and back to agalsidase- $\alpha$ (due to logistic reasons).

This FD cohort was analyzed to characterize the effects of ERT on the renal disease and progress following ERT. First, the relationship of age and eGFR calculated according to Chronic Kidney Disease Epidemiology Collaboration equation (CKD-EPI) [19] at initiation of ERT was investigated in Classical patients not on RRT. Second, a longitudinal analysis with a disease progression model was performed in patients with two or more visits. Only one male was untreated and therefore excluded from the analysis. Baseline characteristics of included patients $(n=67)$ are summarized in Table 1 . The Flow-chart is shown as Figure 1. 


\section{Kidney \\ Blood Pressure Research}

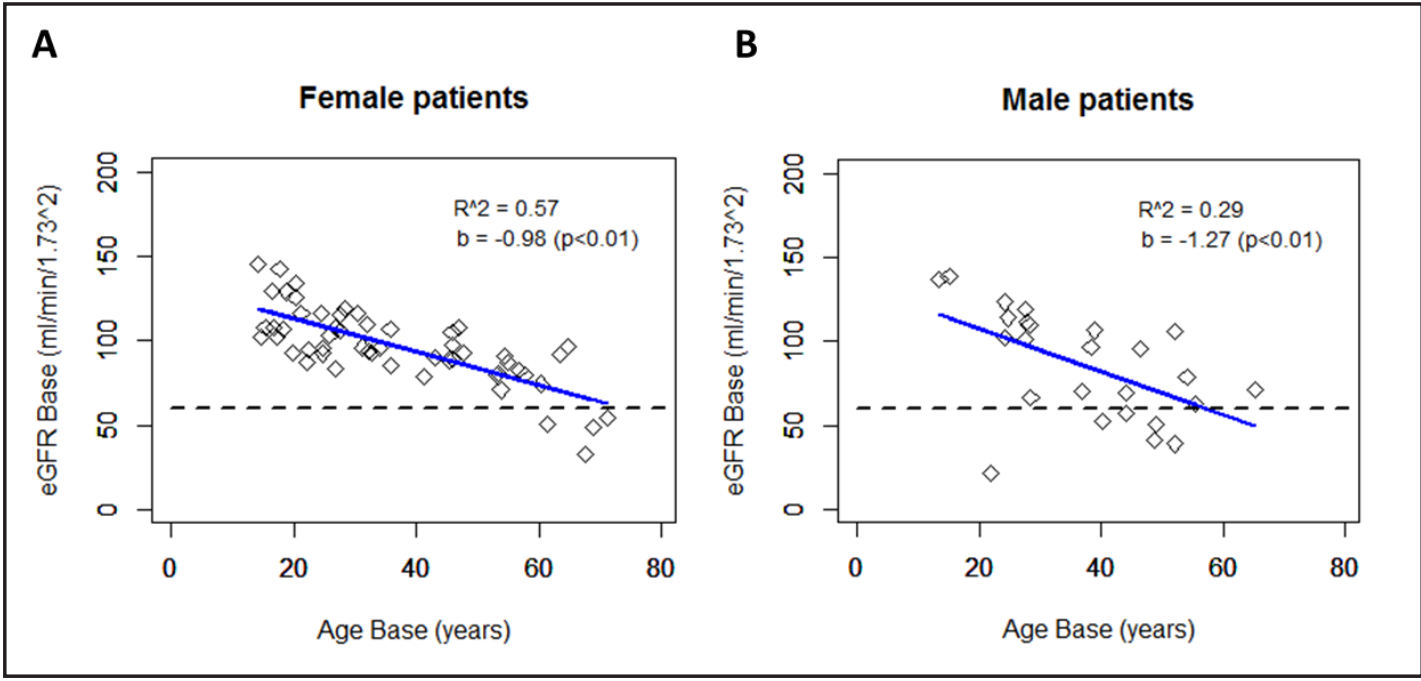

Fig. 2. Relationship of age and eGFR at baseline. The relationship of age and eGFR at baseline is visualized for female $(n=54)$ in the left panel A and male $(n=26)$ in the right panel B. Every diamond corresponds to one patient. Linear regression Eq. (1) is shown as solid blue line and the dashed black line marks beginning of the CKD stage three and higher. Coefficient of determination $\mathrm{R}^{\wedge} 2$ and slope $\mathrm{b}$ are indicated in the panels.

Relationship between age and kidney function: baseline data The relationship of age and eGFR at initiation of ERT was investigated with Eq. (1), i.e. age at baseline vs. eGFR at baseline. Baseline data from female FD patients $(n=54)$ showed a linear relationship with a significant $(\mathrm{p}<0.01)$ negative slope and a reasonable coefficient of determination $\left(\mathrm{R}^{\wedge} 2\right.$ $=0.57$ ). Notably, only $7 \%$ of female FD patients $(\mathrm{n}=$ 4) were staged in CKD $3(<60 \mathrm{ml} /$ $\left.\min / \mathrm{m} 1.73 \mathrm{~m}^{\wedge} 2\right)$ at first visit. The age of these four females was 60 years or higher. Baseline data from male FD patients $(n=25)$ also had a significant $(\mathrm{p}<0.01)$ negative slope, although

Table 2. Baseline characteristics of treated and untreated patients with the Classic phenotype of Fabry disease patients included in disease progression model

\begin{tabular}{|c|c|c|c|}
\hline & $\begin{array}{l}\text { Treated females* } \\
\quad \mathrm{N}=21\end{array}$ & $\begin{array}{l}\text { Untreated females } \\
\qquad \mathrm{N}=22\end{array}$ & $\begin{array}{c}\text { Treated males } \\
\mathrm{N}=24\end{array}$ \\
\hline Age (years) & $36[22,54]$ & $27[21,43]$ & $39[28,49]$ \\
\hline \multicolumn{4}{|l|}{ Enzyme replacement } \\
\hline Agalsidase- $\alpha, \mathrm{n}(\%)$ & $18(86)$ & n.a. & $18(75)$ \\
\hline Agalsidase- $\beta, \mathrm{n}(\%)$ & $3(14)$ & n.a. & $6(25)$ \\
\hline Serum creatinine $(\mu \mathrm{mol} / \mathrm{l})$ & $71[64,75]$ & $71[63,74]$ & $90[82,117]$ \\
\hline $\mathrm{eGFR}\left(\mathrm{ml} / \mathrm{min} / 1.73 \mathrm{~m}^{\wedge} 2\right)$ & $92[87,110]$ & $96[90,107]$ & $96[65,110]$ \\
\hline Urine protein/creatinine, $\mathrm{mg} / \mathrm{mmol}$ & $27[15.3,55]$ & $8[6,11]$ & $18[8,28]$ \\
\hline Urine albumin/creatinine, $\mathrm{mg} / \mathrm{mmol}$ & $3.4[1.2,15]$ & $2.2[1.2,4.8]$ & $26[19,31]$ \\
\hline \multicolumn{4}{|l|}{ Kind of mutation } \\
\hline Missense, n (\%) & $17(81)$ & $11(50)$ & $16(67)$ \\
\hline Deletion, n (\%) & $3(14)$ & $4(18)$ & $5(21)$ \\
\hline Duplication, n (\%) & $0(0)$ & $5(23)$ & $3(12)$ \\
\hline Nonsense, n (\%) & $1(5)$ & $2(9)$ & $0(0)$ \\
\hline Weight (kg) & $56[53,61]$ & $60[54,66]$ & $64[58,72]$ \\
\hline BMI $\left(\mathrm{kg} / \mathrm{m}^{\wedge} 2\right)$ & $22[20,25]$ & $23[20,24]$ & $22[19,23]$ \\
\hline Systolic BP (mmHg) & $124[110,130]$ & $110[105,120]$ & $120[120,130]$ \\
\hline Diastolic BP (mmHg) & $80[75,84]$ & $70[70,80]$ & $80[75,82]$ \\
\hline ACE-inhibitors or ARB, n (\%) & $9(43)$ & $5(23)$ & $17(71)$ \\
\hline $\begin{array}{l}\text { Patients with events during follow- } \\
\text { up }\end{array}$ & 7 & 0 & 10 \\
\hline Events during follow-up & 9 & 0 & 17 \\
\hline \multicolumn{4}{|c|}{$\begin{array}{l}\text { * Primary cause of ERT initiation was acroparesthesia }(\mathrm{n}=8) \text {, cardiomypathy }(\mathrm{n}=7) \text {, stroke }(\mathrm{n}=3) \text {, } \\
\text { renal involvement diagnosed by biopsy }(\mathrm{n}=1) \text {, cardiomypathy and renal involvement }(\mathrm{n}=2) \text {. } \\
\text { Numbers with ranges in square brackets are medians and interquartile ranges. } \\
\text { Abbreviations: ACE, angiotensin-converting enzyme; ARB, angiotensin receptor blocker; BP, blood } \\
\text { pressure; eGFR, estimated glomerular filtration rate; BMI, body-mass index. } \\
\text { To convert the values for creatinine to milligrams per deciliter, divide by } 88 \text {. }\end{array}$} \\
\hline
\end{tabular}




\section{Kidney \\ Blood Pressure Research}

Kidney Blood Press Res 2017;42:1-15

\begin{tabular}{l|l}
\hline DOI: 10.1159/000464312 & (c) 2017 The Author(s). Published by S. Karger AG, Basel
\end{tabular}

Published onlıne: February 28, 2017 www.karger.com/kbr

Nowak et al.: ERT and Kidney Function in Classic FD Phenotype with a lower coefficient of determination $\left(\mathrm{R}^{\wedge} 2<0.29\right)$. In contrast to female FD patients, $24 \%$ of the male FD patients $(n=6)$ were staged in CKD 3 or 4 at first visit. The ages of these six males ranged from 22 to 52 years. One of these six patients showed an eGFR value below $30 \mathrm{ml} / \mathrm{min} / 1.73 \mathrm{~m}^{\wedge} 2$ (CKD stage 4 ). Hence, approximately one-fourth of the male FD patients in the investigated cohort had an already significant renal impairment prior to initiation of ERT. In Figure 2, the results for female (panel A) and male (panel B) subjects are shown. Estimates of model parameters and their variability are summarized in Table 1.

Change in kidney function and covariate effects: longitudinal data

FD patients with more than one creatinine measurement were considered ( $\mathrm{n}=67)$. Baseline characteristics of treated and untreated FD patients are presented in Table 2, the genotype information in Table 3. Among females, 22 were 'untreated' (total number of measurements $=82$ ). To account for the relationship between age and eGFR at initiation of ERT, i.e., age at baseline was a significant covariate on $e G F R_{\text {Base }}(\mathrm{p}<0.05)$, this covariate effect was included in all consecutive disease progression models. After accounting for this age effect on eGFR at baseline, values of mean arterial pressure (MAP), body weight (WT) and body mass index (BMI) at baseline had no influence on $e G F R_{\text {Base }}$ and age at baseline showed no effect on the $e G F R_{\text {Slope }}$ Furthermore, time varying covariates WT, BMI and MAP did not influence the $e G F R_{\text {Slope }}$. Estimates of covariate effects are provided in Table 4.

A total of 45 'treated' FD patients (females, $\mathrm{n}=21$, males, $\mathrm{n}=24$ ) with a total of 317
Table 3. Information about the genotype of the 67 Classic patients who were included into the longitudinal model of the kidney disease progression

\begin{tabular}{|c|c|c|c|}
\hline $\mathrm{Nr}$ & Sex & Mutation & Predicted Aminoacid \\
\hline 1 & $\mathrm{f}$ & c.1167dupT & p.Val390CysfsX9 \\
\hline 2 & $\mathrm{f}$ & c.1167dupT & p.Val390CysfsX9 \\
\hline 3 & $\mathrm{f}$ & c.1167dupT & p.Val390CysfsX9 \\
\hline 4 & $\mathrm{f}$ & c.1167dupT & p.Val390CysfsX9 \\
\hline 5 & $\mathrm{f}$ & c.1055_1057dupCTA & p.Ala352_Met353insThr \\
\hline 6 & $\mathrm{f}$ & c.1147_1149del & p.Phe383del \\
\hline 7 & $\mathrm{f}$ & c.1147_1149del & p.Phe383del \\
\hline 8 & $\mathrm{f}$ & c.744_745delTA & p.Phe383del \\
\hline 9 & $\mathrm{f}$ & c.744_745delTA & p.Phe383del \\
\hline 10 & $\mathrm{f}$ & c.1235_1236delCT & p.Thr412SerfsX38 \\
\hline 11 & $\mathrm{f}$ & c.365delA & p.Asn122IlefsX8 \\
\hline 12 & $\mathrm{f}$ & c.365delA & p.Asn122IlefsX8 \\
\hline 13 & $\mathrm{f}$ & c. $.581 \mathrm{C}>\mathrm{T}$ & p.Thr194Ile \\
\hline 14 & $\mathrm{f}$ & c. $581 \mathrm{C}>\mathrm{T}$ & p.Thr194Ile \\
\hline 15 & $\mathrm{f}$ & c. $581 \mathrm{C}>\mathrm{T}$ & p.Thr194Ile \\
\hline 16 & $\mathrm{f}$ & c. $581 \mathrm{C}>\mathrm{T}$ & p.Thr194Ile \\
\hline 17 & $\mathrm{f}$ & c. $581 \mathrm{C}>\mathrm{T}$ & p.Thr194Ile \\
\hline 18 & $\mathrm{f}$ & c. $581 \mathrm{C}>\mathrm{T}$ & p.Thr194Ile \\
\hline 19 & $\mathrm{f}$ & c. $581 \mathrm{C}>\mathrm{T}$ & p.Thr194Ile \\
\hline 20 & $\mathrm{f}$ & c. $581 \mathrm{C}>\mathrm{T}$ & p.Thr194Ile \\
\hline 21 & $f$ & c. $581 \mathrm{C}>\mathrm{T}$ & p.Thr194Ile \\
\hline 22 & $\mathrm{f}$ & c. $581 \mathrm{C}>\mathrm{T}$ & p.Thr194Ile \\
\hline 23 & $\mathrm{f}$ & c. $1033 \mathrm{~T}>\mathrm{C}$ & p.Ser345Pro \\
\hline 24 & $\mathrm{f}$ & c. $1033 \mathrm{~T}>\mathrm{C}$ & p.Ser345Pro \\
\hline 25 & $\mathrm{f}$ & c. $1033 \mathrm{~T}>\mathrm{C}$ & p.Ser345Pro \\
\hline 26 & $\mathrm{f}$ & c. $1033 \mathrm{~T}>\mathrm{C}$ & p.Ser345Pro \\
\hline 27 & $\mathrm{f}$ & c. $1033 \mathrm{~T}>\mathrm{C}$ & p.Ser345Pro \\
\hline 28 & $\mathrm{f}$ & c. $1033 \mathrm{~T}>\mathrm{C}$ & p.Ser345Pro \\
\hline 29 & $\mathrm{f}$ & c. $704 \mathrm{C}>\mathrm{A}$ & p.Ser235Tyr \\
\hline 30 & $\mathrm{f}$ & c. $125 \mathrm{~T}>\mathrm{C}$ & p.Met42Thr \\
\hline 31 & $\mathrm{f}$ & c. $125 \mathrm{~T}>\mathrm{C}$ & p.Met42Thr \\
\hline 32 & $\mathrm{f}$ & c. $125 \mathrm{~T}>\mathrm{C}$ & p.Met42Thr \\
\hline 33 & $\mathrm{f}$ & c. $125 \mathrm{~T}>\mathrm{C}$ & p.Met42Thr \\
\hline 34 & $\mathrm{f}$ & c. $796 \mathrm{G}>\mathrm{T}$ & p.Asp266Tyr \\
\hline 35 & $f$ & c. $827 \mathrm{G}>\mathrm{A}$ & p.Ser276Asn \\
\hline 36 & $\mathrm{f}$ & c. $154 \mathrm{~T}>\mathrm{C}$ & p.Cys52Arg \\
\hline 37 & $\mathrm{f}$ & c. $72 \mathrm{G}>\mathrm{A}$ & p.Trp24X \\
\hline 38 & $\mathrm{f}$ & c. $901 \mathrm{C}>\mathrm{T}$ & p.Arg301X \\
\hline 39 & $\mathrm{f}$ & c. $901 \mathrm{C}>\mathrm{T}$ & p.Arg301X \\
\hline 40 & $\mathrm{f}$ & c. $488 \mathrm{G}>\mathrm{T}$ & p.Gly163Val \\
\hline 41 & $\mathrm{f}$ & c. $640-3 \mathrm{C}>\mathrm{G}$ & Splicing defect \\
\hline 42 & $\mathrm{f}$ & c. $370-2 \mathrm{~A}>\mathrm{G}$ & Splicing defect \\
\hline 43 & $\mathrm{f}$ & Not available* & Not available \\
\hline 44 & $\mathrm{~m}$ & c.1167dupT & p.Val390CysfsX9 \\
\hline 45 & $\mathrm{~m}$ & c.1167dupT & p.Val390CysfsX9 \\
\hline 46 & $\mathrm{~m}$ & c.1055_1057dupCTA & p.Ala352_Met353insThr \\
\hline 47 & $\mathrm{~m}$ & c.1147_1149del & p.Phe383del \\
\hline 48 & $\mathrm{~m}$ & c.744_745delTA & p.Phe248LeufsX7 \\
\hline 49 & $\mathrm{~m}$ & c.744_745delTA & p.Phe383del \\
\hline 50 & $\mathrm{~m}$ & Deletion whole Exon 2 & Null-allele \\
\hline 51 & $\mathrm{~m}$ & Deletion whole Exon 2 & Null-allele \\
\hline 52 & $\mathrm{~m}$ & c. $581 \mathrm{C}>\mathrm{T}$ & p.Thr194Ile \\
\hline 53 & $\mathrm{~m}$ & c. $581 \mathrm{C}>\mathrm{T}$ & p.Thr194Ile \\
\hline 54 & $\mathrm{~m}$ & c. $581 \mathrm{C}>\mathrm{T}$ & p.Thr194Ile \\
\hline 55 & $\mathrm{~m}$ & c.899T>A & p.Leu300His \\
\hline 56 & $\mathrm{~m}$ & c.899T>A & p.Leu300His \\
\hline 57 & $\mathrm{~m}$ & c. $125 \mathrm{~T}>\mathrm{C}$ & p.Met42Thr \\
\hline 58 & $\mathrm{~m}$ & c. $125 \mathrm{~T}>\mathrm{C}$ & p.Met42Thr \\
\hline 59 & $\mathrm{~m}$ & c. $581 \mathrm{C}>\mathrm{T}$ & p.Thr194Ile \\
\hline 60 & $\mathrm{~m}$ & c. $827 \mathrm{G}>\mathrm{A}$ & p.Ser276Asn \\
\hline
\end{tabular}




\section{Kidney \\ Blood Pressure Research}

Kidney Blood Press Res 2017;42:1-15

\begin{tabular}{l|l}
\hline DOI: 10.1159/000464312 & (C) 2017 The Author(s). Published by S. Karger AG, Base
\end{tabular}

Published online: February 28, 2017 www.karger.com/kbr

Nowak et al.: ERT and Kidney Function in Classic FD Phenotype measurements were available. Sex had a significant effect on $e G F R_{\text {Slope }}$. After accounting for this sex effect, age, WT, BMI and MAP at baseline showed no effects on $e G F R_{\text {Base }}$ or eGFR Slope $_{\text {. }}$

No clear effects of angiotensinconverting enzyme (ACE)inhibitors and angiotensin blockers (ARB) on eGFR slopes were found. Estimates of covariate effects are

\begin{tabular}{llll}
$\triangle$ & & \\
61 & $\mathrm{~m}$ & c.1033T $>\mathrm{C}$ & p.Ser345Pro \\
62 & $\mathrm{~m}$ & $\mathrm{c} .1033 \mathrm{~T}>\mathrm{C}$ & p.Ser345Pro \\
63 & $\mathrm{~m}$ & $\mathrm{c} .1033 \mathrm{~T}>\mathrm{C}$ & p.Ser345Pro \\
64 & $\mathrm{~m}$ & $\mathrm{c} .1033 \mathrm{~T}>\mathrm{C}$ & p.Ser345Pro \\
65 & $\mathrm{~m}$ & $\mathrm{IVS} 6-10 \mathrm{G}>\mathrm{A}$ & Splicing defect \\
66 & $\mathrm{~m}$ & $\mathrm{c} .640-3 \mathrm{C}>\mathrm{G}$ & Splicing defect \\
67 & $\mathrm{~m}$ & c.370-2A $>\mathrm{G}$ & Splicing defect \\
\hline *The original genetic report of this patient, who died in between, \\
was not any more available. The Classic phenotype has been \\
confirmed by clinical symptoms: cardiomyopathy, nephropathy, \\
cornea verticillata, hypohidrosis.
\end{tabular}

Table 4. Model parameters and covariate effects of the longitudinal change in eGFR data analysis

\begin{tabular}{|c|c|c|c|c|}
\hline & & & $\begin{array}{l}\text { Untreated group } \\
\text { female }\end{array}$ & $\begin{array}{l}\text { Treated group } \\
\text { female and male }\end{array}$ \\
\hline Model parameter & Unit & Definition & Estimate (r.s.e) & Estimate (r.s.e) \\
\hline$e G F R_{\text {Base }}$ & $\begin{array}{l}\mathrm{ml} / \mathrm{min} / 1.73 \\
\mathrm{~m}^{\wedge} 2\end{array}$ & eGFR Baseline & $92.7(3)$ & $84.1(4)$ \\
\hline$\beta_{e G F R_{\text {Base }}, A g e_{\text {Base }}}$ & & $\begin{array}{l}\text { Power coefficient of } \\
\text { covariate model }\end{array}$ & $-0.38(15)$ & $-0.41(20)$ \\
\hline$e G F R_{\text {Slope,female }}$ & $\begin{array}{l}\mathrm{ml} / \mathrm{min} / 1.73 \\
\mathrm{~m}^{\wedge} 2 / \text { month }\end{array}$ & eGFR Slope female & $-0.006(>100)$ & $0.0428(>100)$ \\
\hline$e G F R_{\text {Slope,male }}$ & $\begin{array}{l}\mathrm{ml} / \mathrm{min} / 1.73 \\
\mathrm{~m}^{\wedge} 2 / \mathrm{month}\end{array}$ & eGFR Slope male & --- & $-0.256(24)$ \\
\hline$\omega_{\text {eGFR }}$ Base & & Inter-subject variability & $0.105(19)$ & $0.24(11)$ \\
\hline$\omega_{\text {eGFR }}$ Slope & & Inter-subject variability & $0.088(50)$ & $0.29(12)$ \\
\hline$a$ & & Absolut residual error parameter & $13.2(33)$ & $3.1(19)$ \\
\hline$b$ & & Proportion residual error parameter al & $-0.059(73)$ & $0.05(16)$ \\
\hline $\mathrm{AIC}$ & & Akaike information criterion & 614 & 2443 \\
\hline
\end{tabular}

listed in Table 4. Female FD patients without ERT had a slight decrease in eGFR ( $e G F R_{\text {Slope }}=$ $-0.006 \mathrm{ml} / \mathrm{min} / 1.73 \mathrm{~m}^{\wedge} 2 /$ month) (Figure $3 \mathrm{~A}$ ), whereas 'treated' females showed a marginal increase of eGFR over time $\left(e G F R_{\text {Slope }}=0.0428 \mathrm{ml} / \mathrm{min} / 1.73 \mathrm{~m}^{\wedge} 2 / \mathrm{month}\right)$ (Figure 3B). Difference of the eGFR slopes between 'untreated' females and those with ERT was not statistically significant. Further magnitude of ERT effect on eGFR slope was marginal in females with stable, almost unchanged kidney function over time. In contrast, males with ERT had a noticeable decrease of eGFR over time $\left(e G F R_{\text {Slope }}=-0.256 \mathrm{ml} / \mathrm{min} / 1.73 \mathrm{~m}^{\wedge} 2 /\right.$ month), which was significantly different from that observed in females on ERT $(\mathrm{p}<0.01)$ (Figure 3C).

There was no difference in effects of agalsidase- $\alpha$ and $-\beta$ on eGFR slopes. However, the number of patients on agalsidase- $\beta$ was small. The actual administered ERT dose had no clear effect on eGFR slope. In patients with eGFR at baseline below and above $60 \mathrm{ml} /$ $\min / 1.73 \mathrm{~m}^{\wedge} 2$, the eGFR slopes were similar. In addition, a covariate test of eGFR at baseline directly at the slope showed no significant effect.

\section{Analysis of albuminuria and proteinuria}

Protein/creatinine ratios in the urine were available from 46 patients with a total of 174 measurements and albumin/creatinine ratios from 51 patients with a total of 217 measurements. No covariate effects on the slope of these ratios over time were found, especially no ERT dependent difference. At baseline, the urine albumin/creatinine and protein/creatinine ratios were significantly higher in males than in females. However, since longitudinalalbuminuriaand proteinuriadatawereassociated withahighvariability, nodisease 


\section{Kidney \\ Blood Pressure Research}

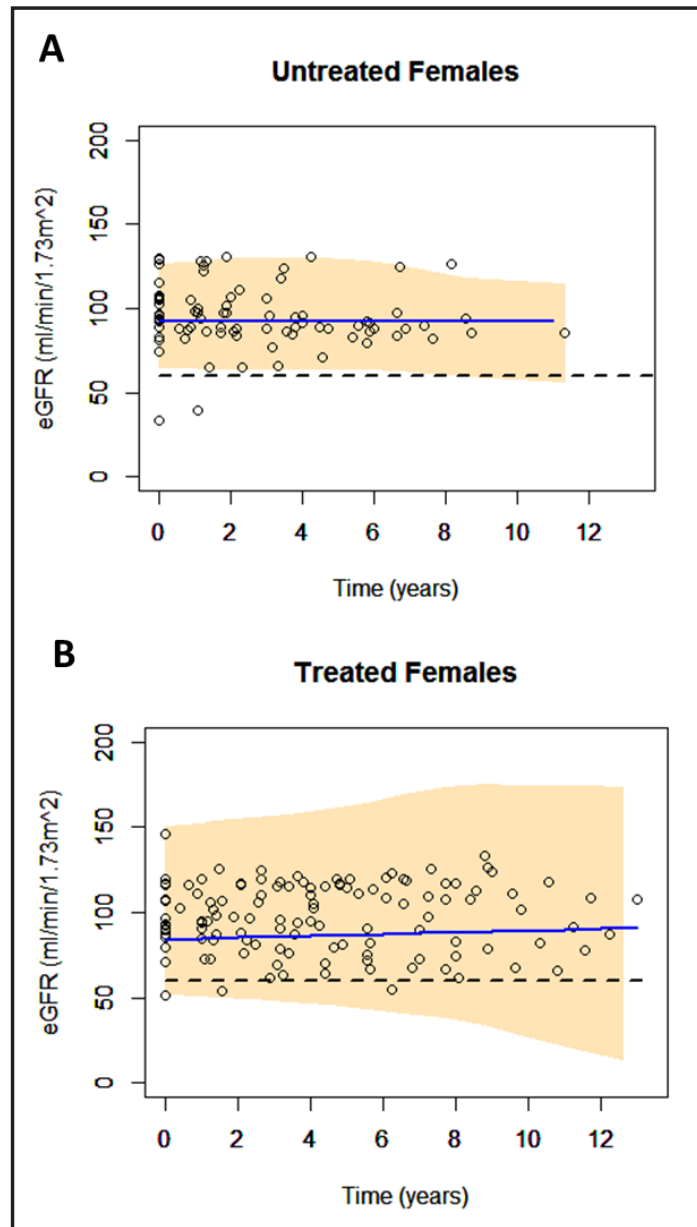

Kidney Blood Press Res 2017;42:1-15

\begin{tabular}{l|l}
\hline DOI: 10.1159/000464312 & (C) 2017 The Author(s). Published by S. Karger AG, Basel
\end{tabular}

Published online: February 28, 2017 www.karger.com/kbr

Nowak et al.: ERT and Kidney Function in Classic FD Phenotype

Fig. 3. The eGFR change over time. Panel A untreated females $(n=22)$, panel B treated females $(\mathrm{n}=21)$ and panel $\mathrm{C}$ treated males $(\mathrm{n}=24)$. The dots represent the eGFR data. The solid blue lines are the mean eGFR change over time of the typical patient obtained by non-linear mixed effect modeling with Eq. (2). Shaded areas visualize the 5 and 95 $\%$ confidence intervals calculated based on 1000 simulated populations.

C

Treated Males

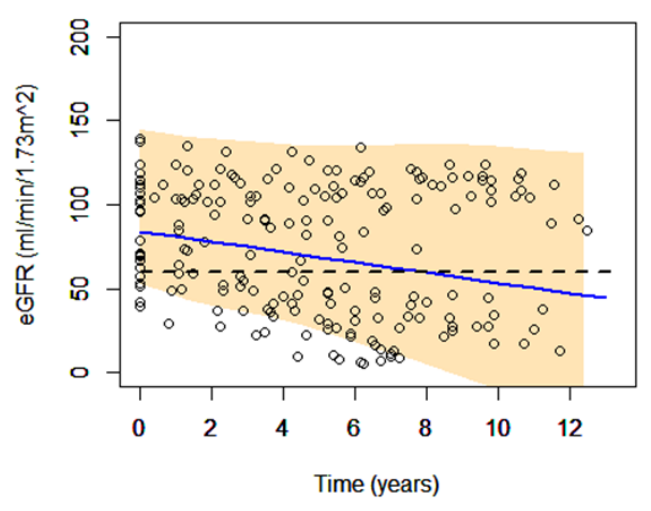

progression model was developed.

Relationship of eGFR slope and albuminuria at baseline

Kidney function decrease over time, characterized by eGFR slopes, was significantly $(\mathrm{p}<0.05)$ less severe in the first (albuminuria at baseline < $3 \mathrm{mg} / \mathrm{mmol}$; median slope $=0.019$ ) and second $(3-30 \mathrm{mg} / \mathrm{mmol}$, median slope $=0.014$ ) group as compared to the the third (> $30 \mathrm{mg} / \mathrm{mmol}$; median slope $=-0.371)$ category (Figure 4).

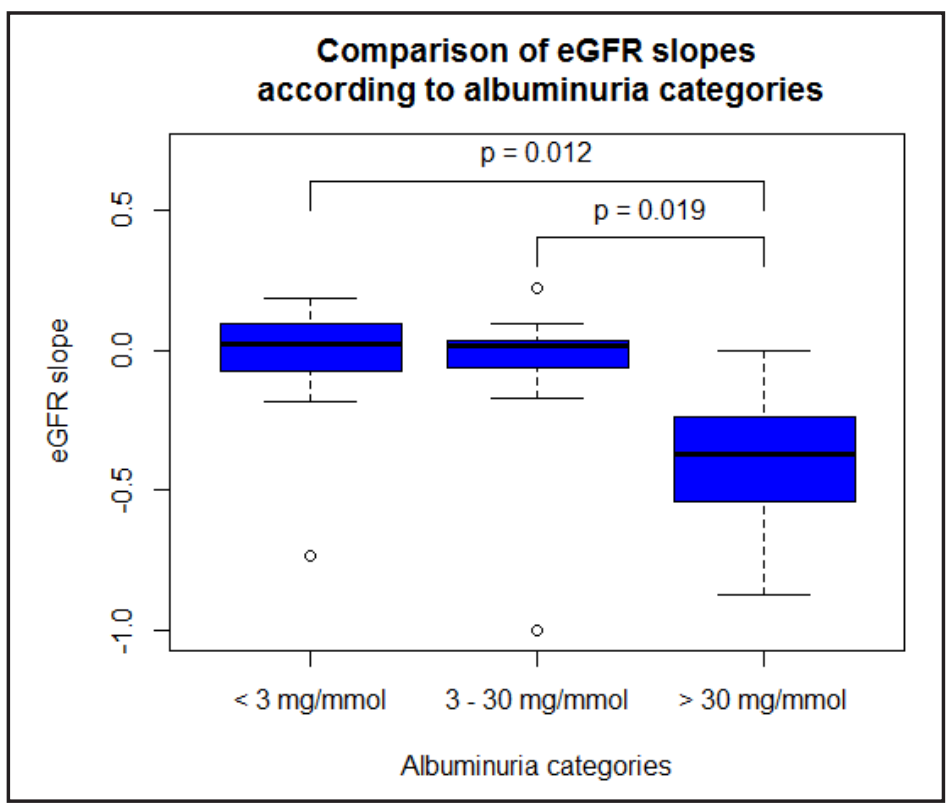

Fig. 4. Comparison of eGFR slopes according to albuminuria categories. 


\section{Kidney Blood Pressure Research}

Relation of eGFR slope and serum-mediated ERT inhibition

Three of 15 treated males showed a significant inhibition of $>50 \%$ : first male currently 52 years old, ERT start with 38 years of age, second male currently 57 years old, ERT start with 44 years of age, third male currently 51 years old, ERT start with 39 years of age. Their eGFR slopes were not significantly different to the non-inhibiting male population (data not shown).

No female showed a significant serum-mediated ERT inhibition in this cohort.

Clinical events

Overall, 27 events occurred in 18 of 67 Classical patients who were included into the dynamic analysis. Among treated females, 1 suffered a new-onset AF, 5 strokes, 1 needed a pacemaker and 2 died (reason unknown). No events occurred among untreated females. Among treated males, 3 patients received a kidney transplantation, 4 suffered a new-onset aerial fibrillation (AF), 4 strokes, 1 myocardial infarction, 2 needed a pacemaker and 3 died (1 due to sepsis, 2 unknown) (Table 2).

Later-Onset phenotype patients

Five males with the mutations c.902G $>A$ (p.Arg301Gln) (two unrelated males); c.1196G>C (p.Trp399Ser); c.352C>T (p.Arg118Cys); c.644A>G (p.Asn215Ser) had a LaterOnset phenotype.

One of the males with the mutation c. $902 \mathrm{G}>\mathrm{A}$ was 51 years old when he was diagnosed and started on ERT with an advanced kidney failure (eGFR of $15 \mathrm{ml} / \mathrm{min} / 1.73 \mathrm{~m}^{\wedge} 2$ ). The other male with the same mutation was 36 years old when he was diagnosed and started on ERT with a normal eGFR and proteinuria of $0.6 \mathrm{~g} / 24$ hours. The male with the mutation c.1196G $>C$ was 42 years old when he was diagnosed with proteinuria of $1.8 \mathrm{~g} / 24$ hours and eGFR of $62 \mathrm{ml} / \mathrm{min} / 1.73 \mathrm{~m}^{\wedge} 2$. He unfortunately rejected ERT. The other two males with c.352C $>\mathrm{T}$ and c. $644 \mathrm{~A}>\mathrm{G}$ were 74 and 36 years old respectively, and had a normal kidney function without proteinuria, both received ERT.

Four females with the mutations, c.902G $>$ A (p.Arg301Gln) (two related females), c.416A>G (p.Asn139Ser), c.337T>C (p.Phe113Leu) had a Later-Onset phenotype.

One of the both females with the mutation c. $902 \mathrm{G}>\mathrm{A}$ (mother) was 61 years old when diagnosed and started on ERT with an eGFR of $88 \mathrm{ml} / \mathrm{min} / 1.73 \mathrm{~m}^{\wedge} 2$ and proteinuria of 0.8 $\mathrm{g} / 24$ hours. Her 25-year-old daughter, had a normal kidney function without proteinuria and needed no ERT. Also the 40-year-old female with the mutation c.416A>G and the 33-year-old with c.337T $>$ C had normal kidney function and needed no ERT.

This group did not form a basis for comparison due to its small sample size and heterogeneity and was therefore excluded from the analysis.

\section{Discussion}

This analysis of a large well documented genetically proven homogeneous group of Classic FD phenotype patients with and without ERT investigated longitudinal eGFR data over a long follow-up period. To account for both, individual and population level disease progression, non-linear mixed effect modelling (NLME) was applied. Although NLME is frequently applied in clinical drug development, to our knowledge, it is the first time that this method was utilized to characterize progression of the Fabry nephropathy over time, quantify effects of ERT, as well as key covariates on kidney function. Previous studies used linear multivariate regression models for outcome analyses as a common statistical tool [16, $31,32]$.

The developed model included the relationship of age at baseline on eGFR at baseline. The finding that kidney function decreases with age is a known fact for the normal population $[33]$ as well as patients with FD $[1,2]$. Agalsidase- $\alpha$ and agalsidase- $\beta$ had a dose-independent 


\section{Kidney Blood Pressure Research}

effects on the development of kidney function in this cohort. Additionally, covariates such as mean arterial pressure, BMI, treatment with ACE-inhibitors and ARB had no influence on the eGFR slope and proteinuria. By modeling, kidney function remained stable in female FD patients without ERT (eGFR slope $-0.07 \mathrm{ml} / \mathrm{min} / 1.73 \mathrm{~m}^{\wedge} 2$ per year) and those with ERT $\left(0.52 \mathrm{ml} / \mathrm{min} / 1.73 \mathrm{~m}^{\wedge} 2\right.$ per year) without a significant difference between these two slopes. In contrast, male FD patients showed a clear decline of kidney function over time despite ERT (eGFR slope $-3.07 \mathrm{ml} / \mathrm{min} / 1.73 \mathrm{~m}^{\wedge} 2$ per year), which appears to be faster than that observed in normal population [33]. According to the developed model, male FD patients can pass through several CKD stages ending up with end-stage renal disease within 15 years after initiation of ERT later in the disease.

Importantly, the majority of symptomatic female patients received ERT because of neurological and cardiovascular symptoms and events. In 3 of 21 treated female patients, ERT was initiated due to FD-related nephropathy. The baseline protein excretion and need of ACE-inhibitors therapy seems to be higher in the treated than in the untreated female group (Table 2). Therefore, the treated female patients might have had a more pronounced kidney involvement at baseline than those without ERT (Table 2). Thus, enzyme replacement therapy could have stabilized the kidney function in these females.

In contrast, ERT showed no clear treatment-related benefit on the development of Fabry nephropathy in male patients in this cohort. One of the possible reasons for the latter observation could be that the initiation of ERT was relatively late, i.e. after 35 years of age. This is an "old" FD population where a great proportion of the patients had advanced kidney disease, when ERT was initiated and offered to all FD patients in 2001. Additionally, as FD is rare, patients experience a delayed diagnosis also resulting in treatment delay [34]. In agreement with our results, a significant loss of renal function over time has repeatedly been demonstrated in patients with FD even under ERT. In an analysis of Fabry Outcome Survey, Beck and co-authors demonstrated for example that the renal disease progression under ERT is more accelerated in patients with already impaired kidney function at baseline [31]. These findings support the assumption that early therapy initiation benefit kidney function.

Of note, the eGFR slopes of the three males with an endogenous serum-mediated inhibition of the recombinant enzyme were not significantly different to the non-inhibiting male population. A possible explanation of this finding is that in this cohort with late ERT initiation, the ERT effects were limited due to the advanced disease stage at baseline in both - inhibiting and non-inhibiting - groups. This finding is in agreement with the main study results. However, these studies are limited since the sample size of inhibiting males is small. Importantly, no female showed a significant serum-mediated ERT inhibition in this cohort, also as shown by Linthorst et al, Rombach et al and Lenders et al [26-28]. This is the first study to show that obviously, classical females do not develop a serum-mediated ERT inhibition even after many years of ERT.

Early FD diagnosis could prevent kidney disease progression through the timely initiation of treatment. As shown in our results, the disease progression was accelerated if ERT patients already had a more severe albuminuria at baseline. Studies suggest that maximal treatment effect in Fabry nephropathy can be achieved at an early stage with normal or almost normal kidney function $[11,35,36]$. Tondel et al have described beneficial effects of ERT detected in kidney biopsies regarding clearance of glomerular endothelial and mesangial cell inclusions in patients with well-preserved renal function $[11,35]$. A recent study by Germain and colleagues showed that less affected individuals with a better preserved kidney function at baseline benefited from ERT, experiencing better renal and cardiovascular outcomes during the observational period [36]. Moreover, in male FD patients, enhanced therapeutic outcomes may occur if we increase the ERT dose $[35,37,38]$, or frequency of infusions [39], in combination with intensified additional medication such as ARBs and ACE inhibitors [16]. In patients with amenable mutations, pharmacological chaperones have been shown as a useful therapeutic alternative $[40,41]$. Their combination with ERT could further increase therapeutic effects [42], this assumption needs to be 


\section{Kidney Blood Pressure Research}

confirmed in clinical studies. Furthermore, enhanced uptake of $\alpha$-gal A into target cells [43] and substrate reduction therapy [44] have been tested in mouse model experiments and can possibly be implemented in human studies in the future, especially in combination with ERT.

It can't be excluded that our male FD patients had experienced treatment benefit despite their deterioration of kidney function. Studies demonstrated a long-term renal stabilization following ERT in FD patients [12, 14, 45, 46]. However, placebo-controlled clinical trials in Fabry nephropathy are scarce and the choice of an appropriate control group in the assessment of the treatment response especially in males remains crucial.

Several limitations merit consideration. First, we included only renal parameters of adolescent and adult FD patients into the longitudinal mathematical model. The time course of eGFR could be non-linear in children with FD. Therefore, further investigations with longitudinal models including pediatric and adult FD patients are warranted. Such expanded model might allow evaluating effects of timely ERT initiation in pediatric males with classical phenotype. Second, we did not test a larger variation of ERT dose on Fabry nephropathy development as the really applied ERT dose did not greatly vary in this cohort. We therefore cannot exclude a possible dose-dependent beneficial effect on Fabry nephropathy. Third, we did not systematically conduct renal biopsies in our patients, also LysoGb3 measurements over time were not available in this "old" FD population. However, follow-up kidney biopsies and LysoGb3 in FD patients could assess treatment response, exclude renal pathologies beyond Fabry nephropathy and confirm diagnosis in uncertain cases [47-49]. Fourth, mathematical disease progression modeling should ideally contain histological findings based on scoring system for renal pathology in Fabry nephropathy [50]. Moreover, early renal tissue biomarkers need to be added to the pharmacometric modeling approaches to develop prognostic markers for pediatric FD patients.

The strength of the study is that we analyzed a large well documented genetically proven homogeneous group including only patients with the Classic phenotype of FD.

\section{Conclusion}

No clear therapeutic effect of enzyme replacement therapy on kidney function in adult patients with Fabry disease was found, presumably because ERT was initiated late in the disease. Interpretation of these findings should take into account that the study is not randomized and lacks a placebo controlled group.

In a future project, mathematical disease progression modeling will be applied to characterize ERT effects on kidney function in pediatric FD patients. Further investigations are warranted to clarify whether earlier ERT initiation, higher ERT dose or more intensive therapies can preserve kidney function, especially in pediatric and adult male FD patients. Mathematical disease progression modeling can add substantial knowledge in the assessment of the therapeutic effects of ERT in female and male FD patients.

\section{Conflict of interest statement}

AN received speaker honoraria and research support from Sanofi-Genzyme and Shire. UH received speaker honoraria from Otsuka and Amgen. The other authors have no disclosures. 


\section{Kidney \\ Blood Pressure Research}

Nowak et al.: ERT and Kidney Function in Classic FD Phenotype

\section{References}

1 Rombach SM, Smid BE, Linthorst GE, Dijkgraaf MG, Hollak CE: Natural course of fabry disease and the effectiveness of enzyme replacement therapy: A systematic review and meta-analysis: Effectiveness of ert in different disease stages. J Inherit Metab Dis 2014;37:341-352.

$>2$ Desnick RJ, Brady R, Barranger J, Collins AJ, Germain DP, Goldman M, Grabowski G, Packman S, Wilcox WR: Fabry disease, an under-recognized multisystemic disorder: Expert recommendations for diagnosis, management, and enzyme replacement therapy. Ann Intern Med 2003;138:338-346.

-3 Pisani A, Visciano B, Imbriaco M, Di Nuzzi A, Mancini A, Marchetiello C, Riccio E: The kidney in fabry's disease. Clin Genet 2014;86:301-309.

-4 Talbot AS, Lewis NT, Nicholls KM: Cardiovascular outcomes in fabry disease are linked to severity of chronic kidney disease. Heart 2015;101:287-293.

-5 Echevarria L, Benistan K, Toussaint A, Dubourg O, Hagege AA, Eladari D, Jabbour F, Beldjord C, de Mazancourt P, Germain DP: X chromosome inactivation in female patients with fabry disease. Clin Genet 2016;89:44-54.

-6 Spada M, Pagliardini S, Yasuda M, Tukel T, Thiagarajan G, Sakuraba H, Ponzone A, Desnick RJ: High incidence of later-onset fabry disease revealed by newborn screening. Am J Hum Genet 2006;79:31-40.

7 von Scheidt W, Eng CM, Fitzmaurice TF, Erdmann E, Hubner G, Olsen EG, Christomanou H, Kandolf R, Bishop DF, Desnick RJ: An atypical variant of fabry's disease with manifestations confined to the myocardium. N Engl J Med 1991;324:395-399.

8 Nakao S, Kodama C, Takenaka T, Tanaka A, Yasumoto Y, Yoshida A, Kanzaki T, Enriquez AL, Eng CM, Tanaka H, Tei C, Desnick RJ: Fabry disease: Detection of undiagnosed hemodialysis patients and identification of a "renal variant" phenotype. Kidney Int 2003;64:801-807.

-9 Shabbeer J, Yasuda M, Benson SD, Desnick RJ: Fabry disease: Identification of 50 novel alpha-galactosidase a mutations causing the classic phenotype and three-dimensional structural analysis of 29 missense mutations. Hum Genomics 2006;2:297-309.

-10 Biegstraaten M, Arngrimsson R, Barbey F, Boks L, Cecchi F, Deegan PB, Feldt-Rasmussen U, Geberhiwot T, Germain DP, Hendriksz C, Hughes DA, Kantola I, Karabul N, Lavery C, Linthorst GE, Mehta A, van de Mheen E, Oliveira JP, Parini R, Ramaswami U, Rudnicki M, Serra A, Sommer C, Sunder-Plassmann G, Svarstad E, Sweeb A, Terryn W, Tylki-Szymanska A, Tondel C, Vujkovac B, Weidemann F, Wijburg FA, Woolfson P, Hollak CE: Recommendations for initiation and cessation of enzyme replacement therapy in patients with fabry disease: The european fabry working group consensus document. Orphanet J Rare Dis 2015;10:36.

11 Tondel C, Bostad L, Larsen KK, Hirth A, Vikse BE, Houge G, Svarstad E: Agalsidase benefits renal histology in young patients with fabry disease. J Am Soc Nephrol 2013;24:137-148.

12 Germain DP, Waldek S, Banikazemi M, Bushinsky DA, Charrow J, Desnick RJ, Lee P, Loew T, Vedder AC, Abichandani R, Wilcox WR, Guffon N: Sustained, long-term renal stabilization after 54 months of agalsidase beta therapy in patients with fabry disease. J Am Soc Nephrol 2007;18:1547-1557.

13 Prabakaran T, Birn H, Bibby BM, Regeniter A, Sorensen SS, Feldt-Rasmussen U, Nielsen R, Christensen EI: Long-term enzyme replacement therapy is associated with reduced proteinuria and preserved proximal tubular function in women with fabry disease. Nephrol Dial Transplant 2014;29:619-625.

14 Mehta A, Beck M, Elliott P, Giugliani R, Linhart A, Sunder-Plassmann G, Schiffmann R, Barbey F, Ries M, Clarke JT, Fabry Outcome Survey i: Enzyme replacement therapy with agalsidase alfa in patients with fabry's disease: An analysis of registry data. Lancet 2009;374:1986-1996.

15 Weidemann F, Niemann M, Stork S, Breunig F, Beer M, Sommer C, Herrmann S, Ertl G, Wanner C: Long-term outcome of enzyme-replacement therapy in advanced fabry disease: Evidence for disease progression towards serious complications. J Intern Med 2013;274:331-341.

16 Warnock DG, Thomas CP, Vujkovac B, Campbell RC, Charrow J, Laney DA, Jackson LL, Wilcox WR, Wanner C: Antiproteinuric therapy and fabry nephropathy: Factors associated with preserved kidney function during agalsidase-beta therapy. J Med Genet 2015;52:860-866.

17 Warnock DG, Ortiz A, Mauer M, Linthorst GE, Oliveira JP, Serra AL, Marodi L, Mignani R, Vujkovac B, BeitnerJohnson D, Lemay R, Cole JA, Svarstad E, Waldek S, Germain DP, Wanner C, Fabry R: Renal outcomes of agalsidase beta treatment for fabry disease: Role of proteinuria and timing of treatment initiation. Nephrol Dial Transplant 2012;27:1042-1049. 


\section{Kidney \\ Blood Pressure Research}

Nowak et al.: ERT and Kidney Function in Classic FD Phenotype

18 Owen J, Fiedler-Kelly J: Introduction to population pharmacokinetic / pharmacodynamic analysis with nonlinear mixed effects models. Wiley \& Sons Inc. 2014.

19 Levey AS, Stevens LA, Schmid CH, Zhang YL, Castro AF, 3rd, Feldman HI, Kusek JW, Eggers P, Van Lente F, Greene T, Coresh J, Ckd EPI: A new equation to estimate glomerular filtration rate. Ann Intern Med 2009;150:604-612.

20 Desnick RJ: Prenatal diagnosis of fabry disease. Prenat Diagn 2007;27:693-694.

21 Desnick R, Ioannou Y, Eng C: A-galactosidase a deficiency: Fabry disease. The metabolic and molecular bases of inherited disease. (eds scriver cr, beaudet al, sly ws, valle d.) p3733-3774, McGraw-Hill, New York, 2001.

-22 Koch G, Walz A, Lahu G, Schropp J: Modeling of tumor growth and anticancer effects of combination therapy. J Pharmacokinet Pharmacodyn 2009;36:179-197.

23 Koch G, Wagner T, Plater-Zyberk C, Lahu G, Schropp J: Multi-response model for rheumatoid arthritis based on delay differential equations in collagen-induced arthritic mice treated with an anti-gm-csf antibody. J Pharmacokinet Pharmacodyn 2012;39:55-65.

24 Zhang L, Feng Y, List J, Kasichayanula S, Pfister M: Dapagliflozin treatment in patients with different stages of type 2 diabetes mellitus: Effects on glycaemic control and body weight. Diabetes Obes Metab 2010;12:510-516.

25 Chapter 1: Definition and classification of ckd. Kidney Int Suppl 2013;3:19-62.

-26 Linthorst GE, Hollak CE, Donker-Koopman WE, Strijland A, Aerts JM: Enzyme therapy for fabry disease: Neutralizing antibodies toward agalsidase alpha and beta. Kidney Int 2004;66:1589-1595.

27 Rombach SM, Aerts JM, Poorthuis BJ, Groener JE, Donker-Koopman W, Hendriks E, Mirzaian M, Kuiper S, Wijburg FA, Hollak CE, Linthorst GE: Long-term effect of antibodies against infused alpha-galactosidase a in fabry disease on plasma and urinary (lyso)gb3 reduction and treatment outcome. PLoS One 2012;7:e47805.

28 Lenders M, Stypmann J, Duning T, Schmitz B, Brand SM, Brand E: Serum-mediated inhibition of enzyme replacement therapy in fabry disease. J Am Soc Nephrol 2016;27:256-264.

29 Lavielle M, Meza H, Chatel K: The monolix software 4.3. Lixoft, Orsay, 2014.

30 Team RC: R: A language and environment for statistical computing. R foundation for statistical computing, Vienna, Austria, 2014.

31 Beck M, Hughes D, Kampmann C, Larroque S, Mehta A, Pintos-Morell G, Ramaswami U, West M, Wijatyk A, Giugliani R, Fabry Outcome Survey Study G: Long-term effectiveness of agalsidase alfa enzyme replacement in fabry disease: A fabry outcome survey analysis. Mol Genet Metab Rep 2015;3:21-27.

-32 Lenders M, Canaan-Kuhl S, Kramer J, Duning T, Reiermann S, Sommer C, Stypmann J, Blaschke D, Uceyler N, Hense HW, Brand SM, Wanner C, Weidemann F, Brand E: Patients with fabry disease after enzyme replacement therapy dose reduction and switch-2-year follow-up. J Am Soc Nephrol 2016;27:952-962.

33 Baba M, Shimbo T, Horio M, Ando M, Yasuda Y, Komatsu Y, Masuda K, Matsuo S, Maruyama S: Longitudinal study of the decline in renal function in healthy subjects. PLoS One 2015;10:e0129036.

-34 Lidove O, Kaminsky P, Hachulla E, Leguy-Seguin V, Lavigne C, Marie I, Maillot F, Serratrice C, Masseau A, Cherin P, Cabane J, Noel E, investigators FI: Fabry disease 'the new great imposter': Results of the french observatoire in internal medicine departments (fimed). Clin Genet 2012;81:571-577.

-35 Skrunes R, Svarstad E, Kampevold Larsen K, Leh S, Tondel C: Reaccumulation of globotriaosylceramide in podocytes after agalsidase dose reduction in young fabry patients. Nephrol Dial Transplant, in press, 2017.

-36 Germain DP, Charrow J, Desnick RJ, Guffon N, Kempf J, Lachmann RH, Lemay R, Linthorst GE, Packman S, Scott CR, Waldek S, Warnock DG, Weinreb NJ, Wilcox WR: Ten-year outcome of enzyme replacement therapy with agalsidase beta in patients with fabry disease. J Med Genet 2015;52:353-358.

-37 Weidemann F, Kramer J, Duning T, Lenders M, Canaan-Kuhl S, Krebs A, Guerrero Gonzalez H, Sommer C, Uceyler N, Niemann M, Stork S, Schelleckes M, Reiermann S, Stypmann J, Brand SM, Wanner C, Brand E: Patients with fabry disease after enzyme replacement therapy dose reduction versus treatment switch. J Am Soc Nephrol 2014;25:837-849.

-38 Warnock DG, Mauer M: Fabry disease: Dose matters. J Am Soc Nephrol 2014;25:653-655.

39 Schiffmann R, Swift C, Wang X, Blankenship D, Ries M: A prospective 10-year study of individualized, intensified enzyme replacement therapy in advanced fabry disease. J Inherit Metab Dis 2015;38:11291136. 


\section{Kidney \\ Blood Pressure Research}

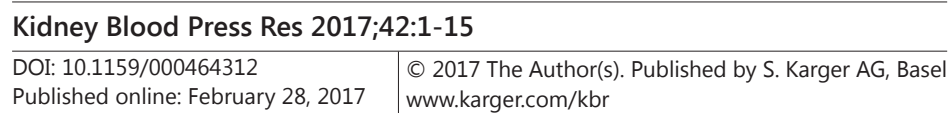

Nowak et al.: ERT and Kidney Function in Classic FD Phenotype

-40 Germain DP, Hughes DA, Nicholls K, Bichet DG, Giugliani R, Wilcox WR, Feliciani C, Shankar SP, Ezgu F, Amartino H, Bratkovic D, Feldt-Rasmussen U, Nedd K, Sharaf El Din U, Lourenco CM, Banikazemi M, Charrow J, Dasouki M, Finegold D, Giraldo P, Goker-Alpan O, Longo N, Scott CR, Torra R, Tuffaha A, Jovanovic A, Waldek S, Packman S, Ludington E, Viereck C, Kirk J, Yu J, Benjamin ER, Johnson F, Lockhart DJ, Skuban N, Castelli J, Barth J, Barlow C, Schiffmann R: Treatment of fabry's disease with the pharmacologic chaperone migalastat. N Engl J Med 2016;375:545-555.

41 Germain DP, Giugliani R, Hughes DA, Mehta A, Nicholls K, Barisoni L, Jennette CJ, Bragat A, Castelli J, Sitaraman S, Lockhart DJ, Boudes PF: Safety and pharmacodynamic effects of a pharmacological chaperone on alpha-galactosidase a activity and globotriaosylceramide clearance in fabry disease: Report from two phase 2 clinical studies. Orphanet J Rare Dis 2012;7:91.

-42 Warnock DG, Bichet DG, Holida M, Goker-Alpan O, Nicholls K, Thomas M, Eyskens F, Shankar S, Adera M, Sitaraman S, Khanna R, Flanagan JJ, Wustman BA, Barth J, Barlow C, Valenzano KJ, Lockhart DJ, Boudes P, Johnson FK: Oral migalastat hcl leads to greater systemic exposure and tissue levels of active alpha-galactosidase a in fabry patients when co-administered with infused agalsidase. PLoS One 2015;10:e0134341.

43 Higuchi K, Yoshimitsu M, Fan X, Guo X, Rasaiah VI, Yen J, Tei C, Takenaka T, Medin JA: Alpha-galactosidase a-tat fusion enhances storage reduction in hearts and kidneys of fabry mice. Mol Med 2010;16:216-221.

44 Ashe KM, Budman E, Bangari DS, Siegel CS, Nietupski JB, Wang B, Desnick RJ, Scheule RK, Leonard JP, Cheng SH, Marshall J: Efficacy of enzyme and substrate reduction therapy with a novel antagonist of glucosylceramide synthase for fabry disease. Mol Med 2015;21:389-399.

45 Feriozzi S, Torras J, Cybulla M, Nicholls K, Sunder-Plassmann G, West M, Investigators FOS: The effectiveness of long-term agalsidase alfa therapy in the treatment of fabry nephropathy. Clin J Am Soc Nephrol 2012;7:60-69.

-46 Tahir H, Jackson LL, Warnock DG: Antiproteinuric therapy and fabry nephropathy: Sustained reduction of proteinuria in patients receiving enzyme replacement therapy with agalsidase-beta. J Am Soc Nephrol 2007;18:2609-2617.

47 van der Tol L, Cassiman D, Houge G, Janssen MC, Lachmann RH, Linthorst GE, Ramaswami U, Sommer C, Tondel C, West ML, Weidemann F, Wijburg FA, Svarstad E, Hollak CE, Biegstraaten M: Uncertain diagnosis of fabry disease in patients with neuropathic pain, angiokeratoma or cornea verticillata: Consensus on the approach to diagnosis and follow-up. JIMD Rep 2014;17:83-90.

48 Niemann M, Rolfs A, Stork S, Bijnens B, Breunig F, Beer M, Ertl G, Wanner C, Weidemann F: Gene mutations versus clinically relevant phenotypes: Lyso-gb3 defines fabry disease. Circ Cardiovasc Genet 2014;7:8-16.

49 Nowak A, Mechtler TP, Desnick RJ, Kasper DC: Plasma lysogb3: A useful biomarker for the diagnosis and treatment of fabry disease heterozygotes. Mol Genet Metab 2016, Doi 10.1016/j.ymgme.2016.10.006.

50 Fogo AB, Bostad L, Svarstad E, Cook WJ, Moll S, Barbey F, Geldenhuys L, West M, Ferluga D, Vujkovac B, Howie AJ, Burns A, Reeve R, Waldek S, Noel LH, Grunfeld JP, Valbuena C, Oliveira JP, Muller J, Breunig F, Zhang X, Warnock DG, all members of the International Study Group of Fabry N: Scoring system for renal pathology in fabry disease: Report of the international study group of fabry nephropathy (isgfn). Nephrol Dial Transplant 2010;25:2168-2177. 